\title{
High Prevalence Of Pre-diabetes And Diabetes In Psychiatric Inpatients
}

Pratyusha Naidu, Alvin Kong, Leonid Churilov, Richard Kaanan, Henry Wong, Arielle Van Mourik, Anthony Yao, Elizabeth Cornish, Graeme K Hart, Elizabeth Owen-Jones, Raymond Robbins, Que Lam, Jeffrey Zajac, Elif I.Ekinci

Department of Endocrinology, Austin Hospital, Melbourne. The University of Melbourne, Australia

\section{BACKGROUND}

- Atypical anti-psychotics have been attributed to the development of pre-diabetes and diabetes in psychiatric patients. ${ }^{(1,2)}$

- However, the role of other factors has been less studied.

\section{AIM}

- We aimed to determine the prevalence, the characteristics and outcomes of psychiatry inpatients with pre-diabetes and diabetes.

\section{METHODS}

- Included were inpatients aged $>30$ years at the Austin psychiatry unit (February-2014 to April-2015)

- $\mathrm{HbA} 1 \mathrm{c}$ measurements through the Diabetes Discovery Initiative.

- Patients were divided into three groups -diabetes $(\mathrm{HbA} 1 \mathrm{c} \geq 6.5 \%$, $48 \mathrm{mmol} / \mathrm{mol}$ ), pre-diabetes (HbA1c $5.7-6.4 \%, 39 \mathrm{mmol} /$ $\mathrm{mol}-46 \mathrm{mmol} / \mathrm{mol}$ ) and no diabetes (HbA1c $\leq 5.6 \%, 38 \mathrm{mmol} / \mathrm{mol})$.

- Data on baseline characteristics, co-morbidities, psychiatric illnesses and treatment were collected.

\section{RESULTS:}

- The distribution of 335 psychiatry inpatients is shown in Figure 1

- The distribution of baseline psychiatric diagnosis and psychotropic medications are shown in Figure 2 and 3.

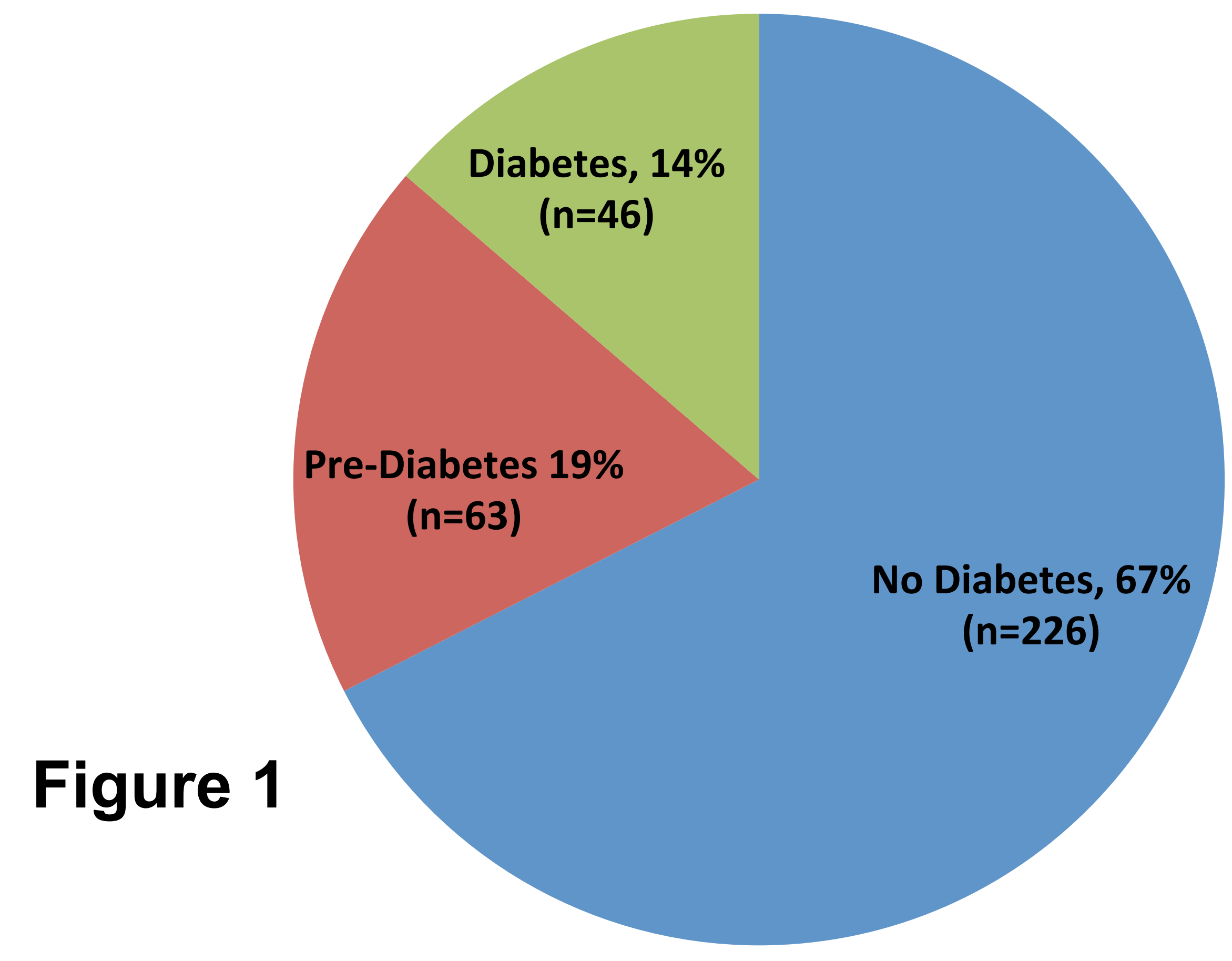

Table 1: Multivariable association of risk factors with diabetes status.

\begin{tabular}{|llll|}
\hline \multicolumn{3}{l}{ Diabetes vs No diabetes and Pre-diabetes } \\
$\begin{array}{l}\text { Clinical } \\
\text { Characteristics }\end{array}$ & Odds Ratio & $\begin{array}{l}\text { 95\% Confidence } \\
\text { Interval }\end{array}$ & \\
\hline Age & 1.04 & 1.01 to 1.07 & 0.02 \\
\hline $\begin{array}{l}\text { Schizoaffective } \\
\text { disorder }\end{array}$ & 0.18 & 0.02 to 1.36 & 0.1 \\
\hline $\begin{array}{l}\text { Substance } \\
\text { Abuse }\end{array}$ & 2.13 & 1.03 to 4.43 & 0.04 \\
\hline $\begin{array}{l}\text { Aripiprazole } \\
\text { Hypertension }\end{array}$ & 1.26 & 1.51 to 12.83 & 0.01 \\
\hline Hyperlipidemia & 2.88 & 0.46 to 3.45 & 0.65 \\
\hline Obesity & 1.96 & 1.14 to 7.26 & 0.03 \\
\hline Employed & 0.57 & 0.90 to 4.26 & 0.09 \\
\hline
\end{tabular}

- Patients with diabetes and pre-diabetes were older (median age 49 and 46 versus $40, p=<0.001$ ) compared to patients without diabetes.

- Patients with diabetes were at least twice as likely to have hypertension, obesity and hyperlipidaemia (all $p \leq 0.002$ ).

- Multivariable analysis revealed the significant variables associated with diabetes to be age, substance abuse hyperlipidemia and aripiprazole use.

- Patients with diabetes also had a longer inpatient stay (Incidence Rate Ratio-1.7, 95\%Cl:1.2-2.3;p=0.001).

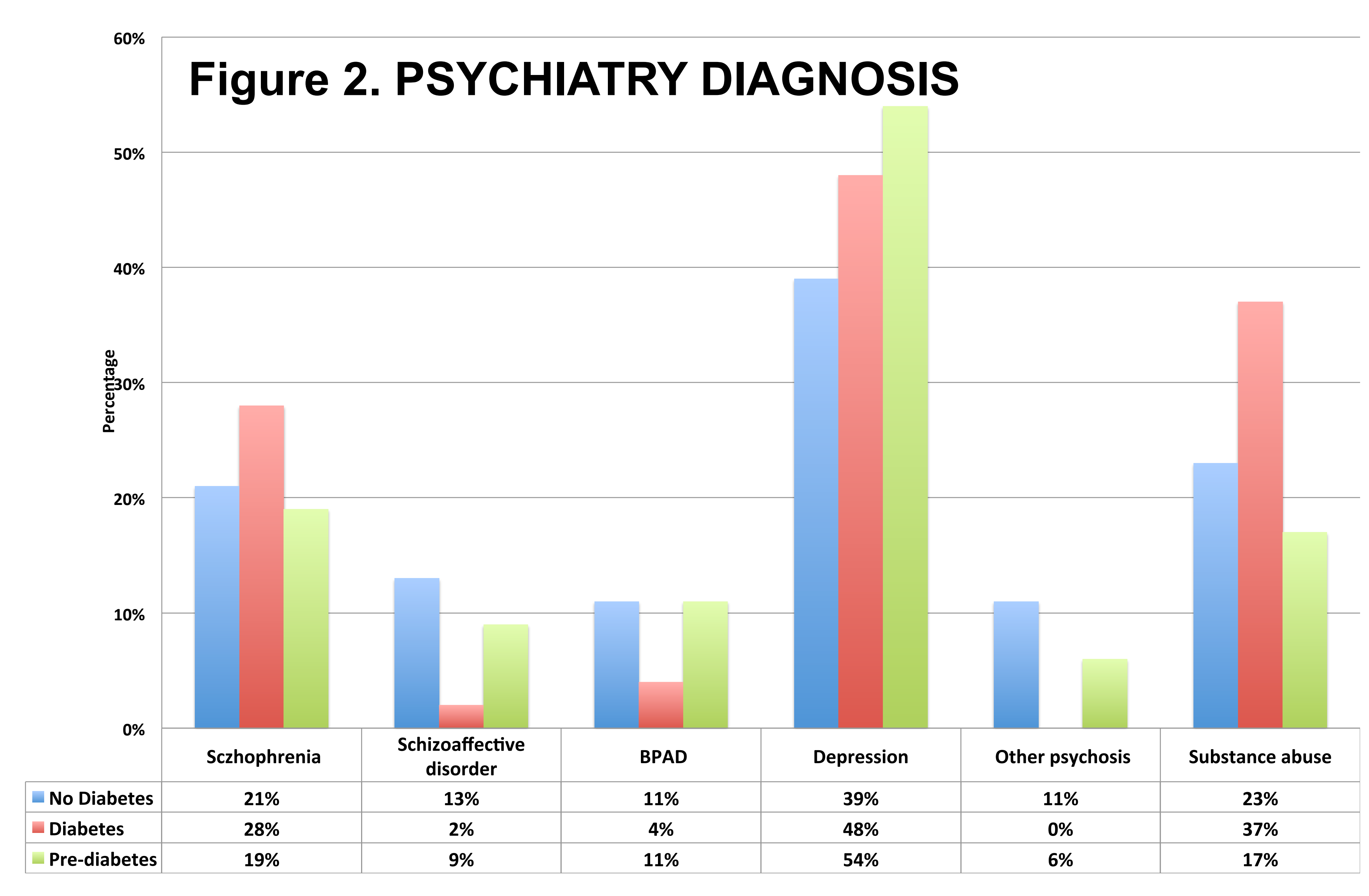

Figure 3: PSYCHOTROPIC MEDICATIONS

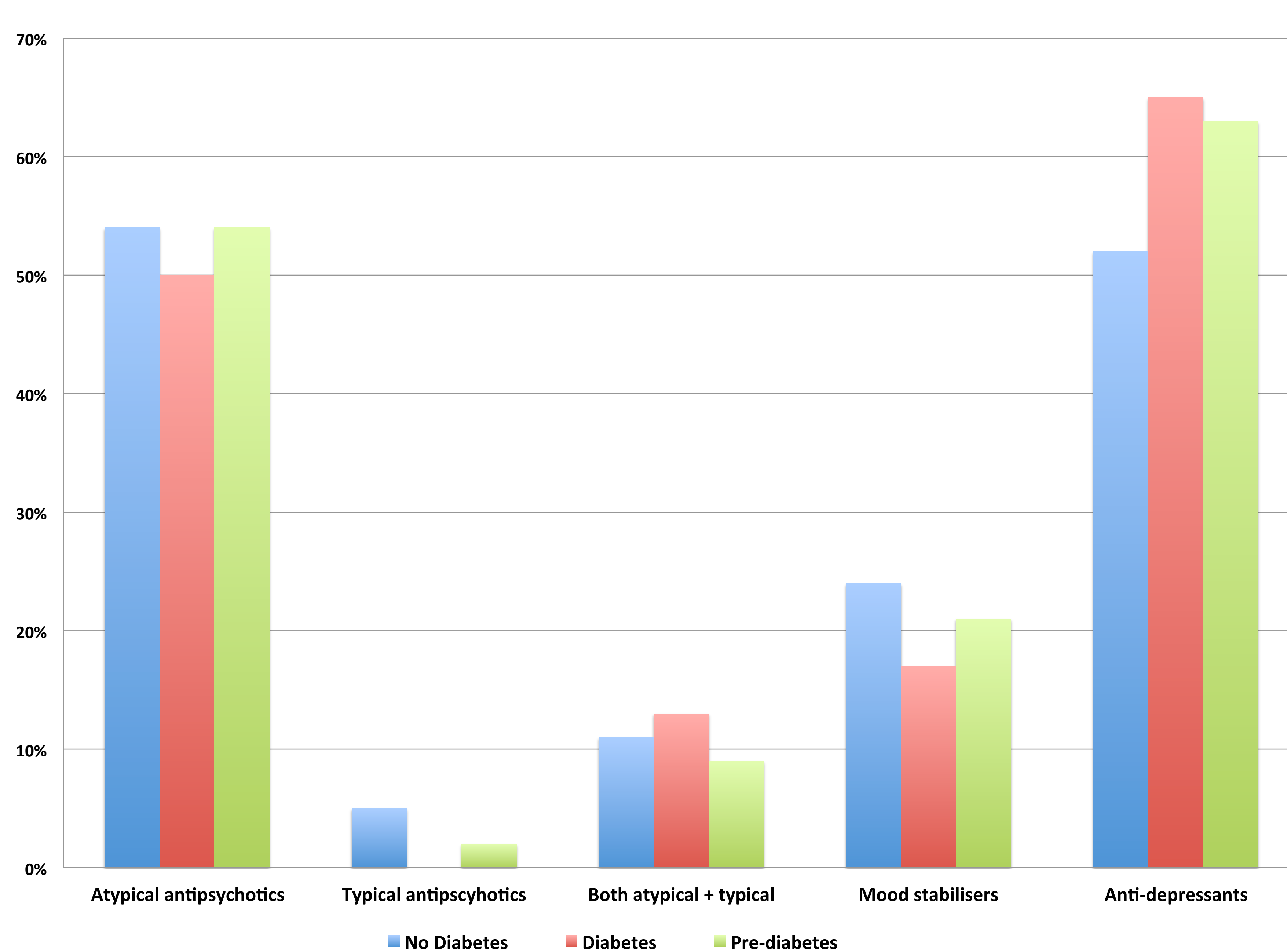

CONCLUSION:

Despite relative youth, one third of all psychiatric inpatients have diabetes or pre-diabetes. Presence of diabetes in psychiatric inpatients is associated with older age, substance abuse and longer hospital admission. The management of glycaemic status in psychiatric inpatients following discharge is difficult and hence routine $\mathrm{HbA1c}$ measurement as an inpatient presents an opportunity to address glycaemic management.

REFERENCES

1) People living with Psychotic Illness 2010, AustralianGovernment, 2011

2) Diabetes , Psychotic Disorders and Antipsychotic therapy- A consensus statement, A/Prof Tim Lambert Dr Leon Chapman , 2004 